\title{
Feature level fusion of vibration and acoustic emission signals in tool condition monitoring using machine learning classifiers
}

\author{
P. Krishnakumar ${ }^{1}$, K. Rameshkumar ${ }^{2}$, K. I. Ramachandran ${ }^{3}$ \\ 1,2,3 Department of Mechanical Engineering, Amrita School of Engineering, Coimbatore, \\ Amrita Vishwa Vidyapeetham, India -641112 \\ p_kkumar@cb.amrita.edu \\ k_rameshkumar@cb.amrita.edu \\ ki_ram@cb.amrita.edu
}

\begin{abstract}
To implement the tool condition monitoring system in a metal cutting process, it is necessary to have sensors which will be able to detect the tool conditions to initiate remedial action. There are different signals for monitoring the cutting process which may require different sensors and signal processing techniques. Each of these signals is capable of providing information about the process at different reliability level. To arrive a good, reliable and robust decision, it is necessary to integrate the features of the different signals captured by the sensors. In this paper, an attempt is made to fuse the features of acoustic emission and vibration signals captured in a precision high speed machining center for monitoring the tool conditions. Tool conditions are classified using machine learning classifiers. The classification efficiency of machine learning algorithms are studied in time-domain, frequencydomain and time-frequency domain by feature level fusion of features extracted from vibration and acoustic emission signature.
\end{abstract}

\section{INTRODUCTION}

Various sensors are used in tool condition monitoring to classify the tool conditions with an objective of improving the productivity in a metal cutting environment. It is well known fact that variation in parameters such as cutting forces, vibration, acoustic emission, temperature, motor current, etc. are some of the indicators for identifying different conditions of the cutting tools such as good, worn-out, tool breakage, and chipping etc. Process monitoring and control can be achieved by detecting tool conditions in real time and cutting tools can be replaced using adaptive control methods without inspecting the condition of tools using offline methods. The

Krishnakumar et al. This is an open-access article distributed under the terms of the Creative Commons Attribution 3.0 United States License, which permits unrestricted use, distribution, and reproduction in any medium, provided the original author and source are credited. essential elements of tool condition monitoring system are shown in the Figure 1 (Zhang et al., 2016).

A typical tool condition monitoring system consists of sensors for monitoring the tool condition, signal processing unit and related hardware and software for tool condition classification and monitoring. In tool condition monitoring systems, tool conditions are generally correlated using signals received from sensors such as sound, optical, vibration, current, force and acoustic emission (Teti et al., 2010).

\begin{tabular}{|c|c|c|c|c|}
\hline Machining & Signals & $\begin{array}{l}\text { Signal processing } \\
\text { (Features) }\end{array}$ & Classifiers & Tool State \\
\hline & & & & \\
\hline $\begin{array}{l}\text { Machining } \\
\text { Set-up and } \\
\text { Sensors }\end{array}$ & $\begin{array}{l}\text { - Force } \\
\text { - Acoustic } \\
\text { Emission (AE) } \\
\text { - Vibration } \\
\text { - Power } \\
\text { - Temperature }\end{array}$ & $\begin{array}{l}\text { - Amplitude } \\
\text { analysis } \\
\text { - Fourier } \\
\text { analysis } \\
\text { - Wavelet } \\
\text { analysis } \\
\text { - Statistical } \\
\text { moments } \\
\text { - Time series } \\
\text { analysis }\end{array}$ & $\begin{array}{l}\text { - Time series } \\
\text { - Linear discriminate analysis } \\
\text { - Fuzzy clustering approaches } \\
\text { - } \text { Geural Nets } \\
\text { - Regrian Mixture models } \\
\text { - } \text { models } \\
\text { - Sidden - Morport Nectov modelor machines } \\
\text { - Rough sets }\end{array}$ & $\begin{array}{ll}\text { - } & \text { Wear } \\
\text { - Chipping } \\
\text { - Breakage } \\
\text { - Cailure } \\
\text { Chatter }\end{array}$ \\
\hline
\end{tabular}

Figure 1. Tool condition monitoring framework

Acoustic Emission (AE) and vibration based techniques are found to be very effective in monitoring the tool conditions in a variety of metal cutting operations. During metal cutting, cutting forces are generated. These cutting forces produce self-excited vibrations. These vibrations are the primary cause for the surface roughness generated during the machining process. Accelerometers are used for the measurement of acceleration produced during metal cutting operation. Accelerometers generate electrical signals based on the amplitude of the vibration of the equipment where the sensor is attached. A typical vibration measurement chain is shown in the Figure 2. Many researchers studied the tool conditions using vibration signatures for identifying the tool conditions for various metal cutting processes. Dimla, D. E. (2002) extracted vibration features and correlated with the tool wear in a turning process. Salgado et al. (2009) predicted surface roughness in a turning process using vibration signature. A study has been carried out by Zhong et al. (2010) 
in a milling operation using vibration signals with and without lubricants. Lamraoui et al. (2014) studied chatter and its influence in a milling process. Tool conditions in a high speed precision milling machine was studied by Krishnakumar et al. (2015) using vibration signals. Tool condition classification efficiency of various machine learning algorithms was studied by them. Zhang et al. (2016) used wireless sensors and tool prognostic studies have been carried out using vibration signals.

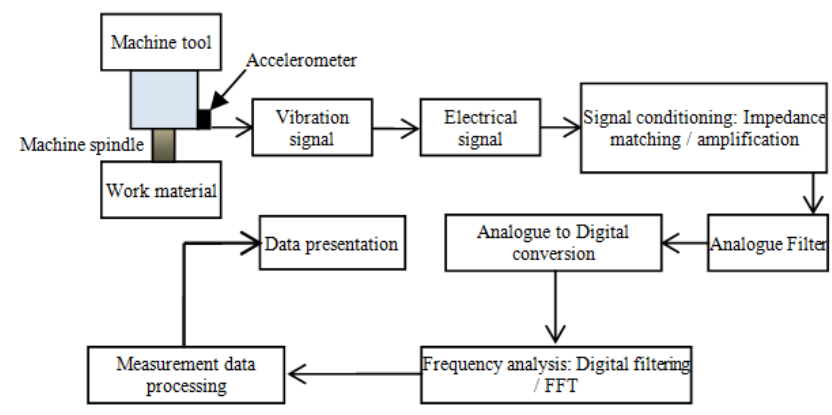

Figure 2.Vibration signature measurement chain

AE sensors are used to detect high frequency elastic waves that are generated during the metal cutting process (Dornfeld, D. A. (1991). Piezo-electric sensor is attached with the workpiece using a suitable couplent. The transient and continuous elastic waves generated during the machining process are sensed by the piezo-electric sensor. The sensor output is amplified by the low-noise pre-amplifier. The signals are further filtered to remove the unnecessary noise present in the signals usually occur at lower frequencies. It is to be noted that $\mathrm{AE}$ will happen in the higher frequency range from 100 $\mathrm{KHz}$ to $1 \mathrm{MHz}$. The main advantage of $\mathrm{AE}$ based tool condition monitoring is that AE signal will not meddle with the cutting process. The frequency range of the AE emissions is much higher than the vibration signals. The unwanted noise during the cutting process can be easily filtered out. The AE signature produced during machining operation is of transient and continuous in nature. The features of $\mathrm{AE}$ signature will have an influence on the tool wear and the surface roughness generated on the work piece (Lamraoui et al. 2014). AE has been used widely to detect the tool conditions by the researchers. Ravindra et al. (1997) correlated the acoustic emission signal with the tool wear in metal cutting operation. Inasaki, I. (1998) studied the application of AE sensors for various metal cutting processes. Hutton and $\mathrm{Hu}$ (1999) carried out time domain studies in end milling operation using AE signature. Karpuschewski et al. (2000) used power and $\mathrm{AE}$ sensors for monitoring the grinding process. Marinescu and Axinte (2008) studied the tool and work piece malfunction in a milling process using AE signature. Han and $\mathrm{Wu}$ (2013) analyzed the AE in a precision grinding process. Cutting phenomenon in turning process was studied by Hase et al. (2014) with the AE signal. Arun et al. (2018) studied cylindrical grinding process using AE sensor.
A comprehensive review detailing sensors, signal processing methods and application areas were presented by the researchers in the recent past (Teti et al.,2010; Roth et al., 2010; Stavropoulos et al., 2013; Lauro et al., 2104; Bhuiyan et al.,2016).

The principle of AE measurement is shown in Figure 3. In this study, AE and vibration sensors are used to detect the tool conditions during machining. Signal processing is carried out and tool conditions are identified using machine learning classifiers.

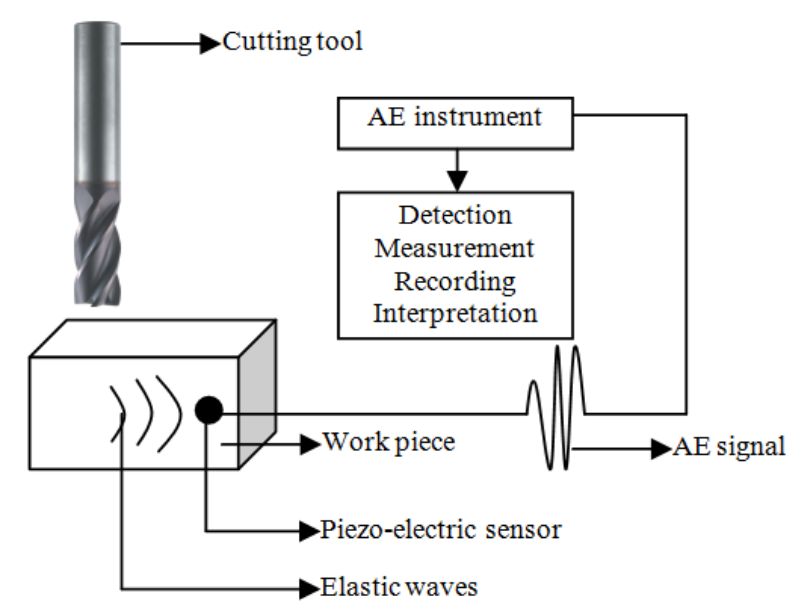

Figure 3. AE measurement system

\subsection{Signal processing}

The raw analogue signal acquired from the sensors contains wealthy information about the condition of the tool. From the raw signal, it is difficult to make a decision about the condition of the tool. It is important to process the raw signals to derive suitable useful information from the signal. The analogue signal has to be filtered, amplified and transformed into digital structure in the pre-preprocessing stage. The signals from the metal cutting process like milling is a nonlinear and non-stationery. Some of the significant signals processing techniques are time-domain analysis, frequency domain analysis and time-frequency domain analysis. The important steps in the signal processing of vibration and $\mathrm{AE}$ signal in time domain and frequency domain are shown in Figure 4.

Time-frequency domain analysis is used to study the signal in both time and frequency domains concurrently (Zhu et al., 2009). In frequency domain analysis there is no time component of the signal. In time domain analysis there is no frequency component. Time-frequency formulations can be made using short time Fourier transforms, wavelet transforms, and bilinear time-frequency distribution and modified Wigner distribution function. 


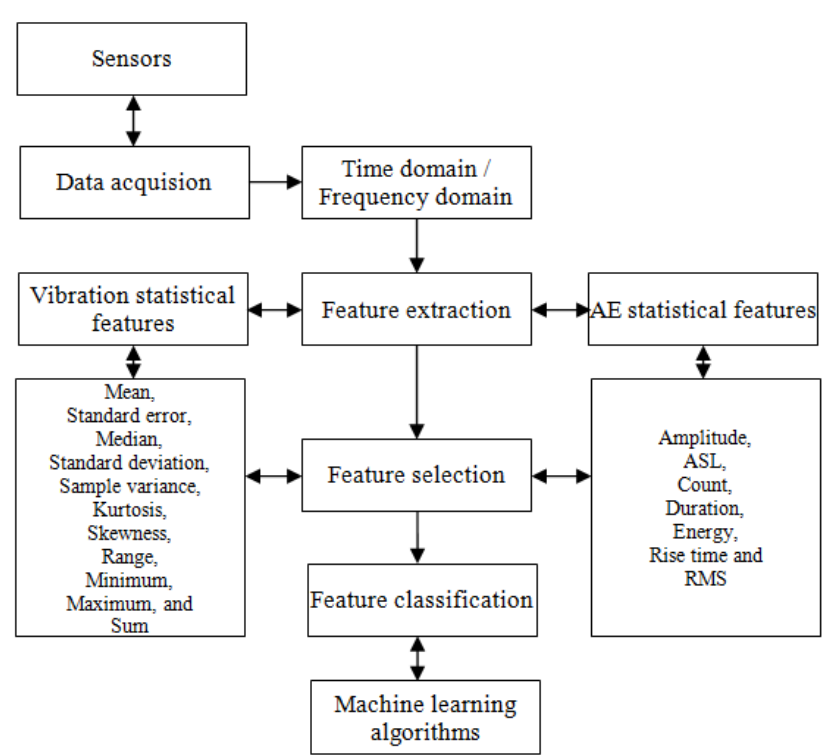

Figure 4. Signature analysis in time-domain and frequencydomain

\section{SENSOR FUSION}

Sensor fusion is the integration of information acquired from the various sensors (Hall, and Llinas, 1997). The resulting information after integration is better than the informations derived from the sensors separately. We have considered sensor fusion in this work with an intension of achieving high signal-to-noise ratio, higher reliability in case of failure of a sensor, lesser uncertainty, and higher resolution of the results obtained from the multiple sensors.

Different types of configurations are used in sensor fusion such as parallel, serial and combination of parallel and serial was presented by Acharya (2015). In parallel configuration, the individual sensors collect the tool condition data from the metal cutting operation. The collected data will be sent to the dedicated processor for decision making. The decision made by the processor will be sent to data fusion center for global decision making. The architecture is shown in the Figure 5. In the serial architecture, sensors collect the information and the information is processed by the individual processors. After processing, the decision will be taken based on its own information and as well as information received for the preceding sensor information. The last sensor processor take the collective decision integrating the informations received from the previous sensors processors in a tandem manner as shown in Figure 6. A tree topology based on parallel and serial and combination is also used in practice for sensor fusion is shown in the Figure 7. In this study, serial topology used for fusing the vibration and $\mathrm{AE}$ signature for tool condition prediction.

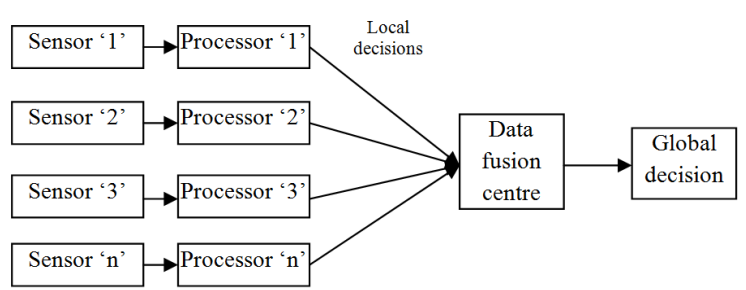

Figure 5. Sensor fusion - Parallel topology

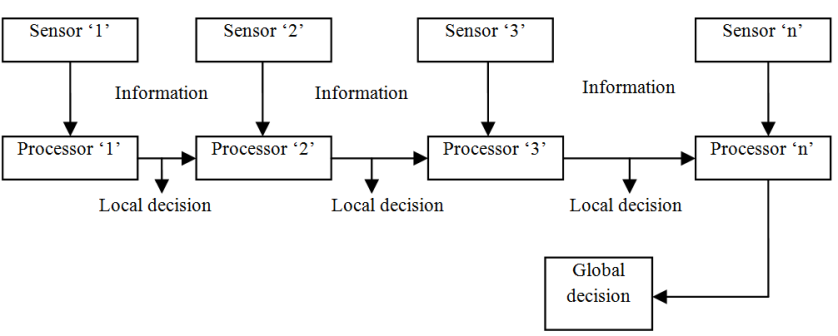

Figure 6. Sensor fusion - Serial topology

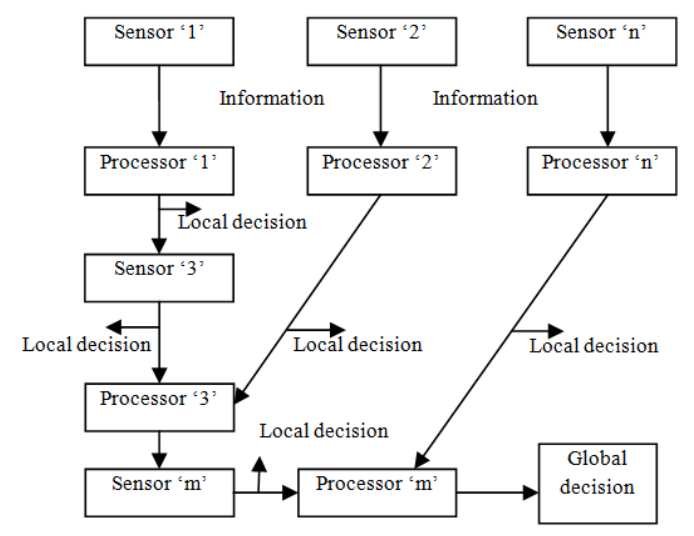

Figure 7. Sensor fusion - Tree topology

\subsection{Decision level and feature level fusion}

There are two techniques for fusion of sensor information, one is at decision level and the other is at feature level (Gunatilaka and Baertlein, 2001). In decision level method, system using single sensor or multi sensors work as a decision maker within its feature space. After making individual decision, all the decisions are pooled together and an opinion is made by based on majority vote rule. The methodology is shown in the Figure 8. Feature is a parameter extracted from the raw signature which is having rich information relevant to the problem considered for the study. In feature level fusion method, features from multiple sensors are pooled into a single set, and the combined data set is fed to the classifiers for tool condition identification. Individual classifiers will have larger input data space and this may affect the accuracy in classification. Feature level fusion gives advantages like redundancy and complementariness. Feature level fusion methodology is shown in Figure 9. 


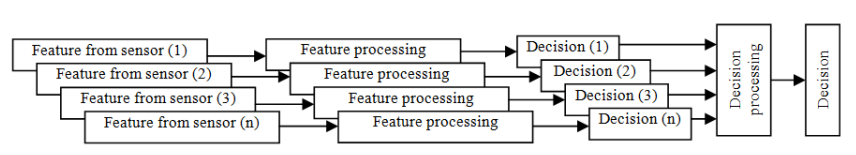

Figure 8. Decision level fusion

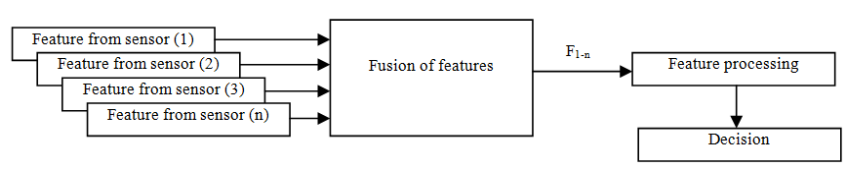

Figure 9. Feature level fusion

Aliustaoglu et al., (2009) proposed a fuzzy based tool wear monitoring system using sensor fusion approach. Cho et al., (2009) designed a multiple sensor fusion model for milling tool condition prediction. Wang et al., (2007) developed an on-line tool condition monitoring for milling operation using sensor fusion approach. Banerji and Das (2012) carried out data fusion for motor fault detection. Saimurugan and Nithesh (2016) proposed a fault analysis model for rotary machinery using sound signals based on data fusion. Results observed by many researches shows that there is an improvement in fault detection efficiency by incorporating fusion approach and fusion approach is suitable for developing an on-line monitoring system. In this study, feature level fusion of $\mathrm{AE}$ and vibration data was carried out. Machine learning algorithms are utilized to predict the tool conditions.

\section{TOOL CONDITION MONITORING: EXPERIMENTAL SETUP}

The overall methodology and experimental set-up established in this study is shown in the Figure 10. In this study, the vibration and acoustic emission sensors were used to acquire signals for monitoring tool conditions during the precision high speed machining of titanium alloy. Signal processing is carried out and relevant features containing information about the tool conditions were extracted in time-domain, frequency domain and time-frequency domain. Machine learning algorithms were used to classify the tool conditions. With an objective of improving the classification efficiency, the information content of $\mathrm{AE}$ and vibration sensors at fused at feature level. The statistical features from vibration and acoustic emission signal features are combined into a single matrix and given as input to the classifiers to identify the state of the tool.

Piezo-electric accelerometer is mounted on the spindle head for measuring the vibration signals generated during machining. The accelerometer is connected to FFT analyzer (signal-conditioning unit), where the acquired signals go through a charge amplifier and an analogue-to-digital converter (ADC). The vibration signal in digital form is fed to the computer through a USB port. The software RT Proseries that accompanies the signal conditioning unit is used for recording the signals directly in the system memory. FFT analyser used in this study is supplied by Dytran Instruments, USA. The sampling frequency was set to $12 \mathrm{kHz}$ and sampling length chosen was 8192 samples per signal.

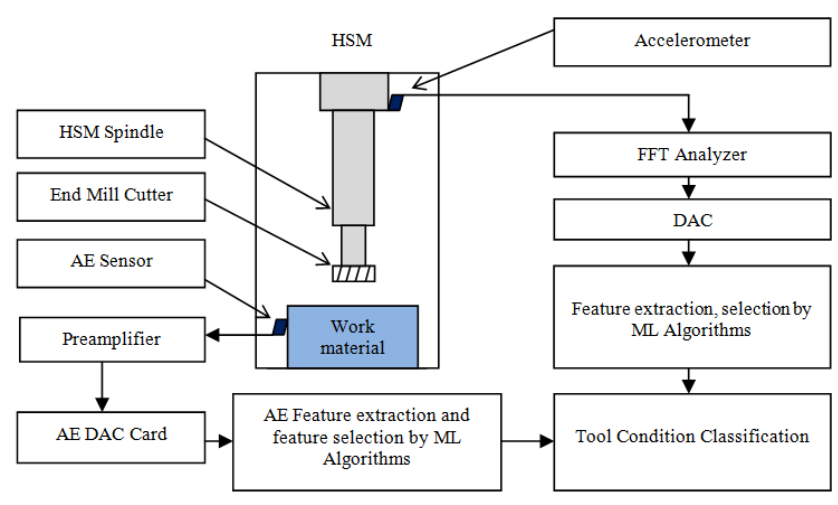

Figure 10. Experimental set-up

AE sensor used in this study is 'Micro 30D' and its operating frequency is 100 to $350 \mathrm{kHz}$. 'Micro-30D' is a differential sensor designed for applications where high background noise is a major concern. The two signal leads from the sensing element feed into a differential pre-amplifier which eliminates common-mode noise resulting in a lower noise output from the pre-amplifier. The AE sensor is mounted on the work-piece material. AE sensor along with the data acquisition card and software ('AE-Win') were supplied by Physical Acoustics Corporation (PAC), USA. The sampling rate of 1 MSPS is chosen for collecting the AE data during machining.

A precision high speed milling machine is used for machining titanium alloy with optimum cutting parameters. Titanium alloys are very hard to machine due to their low thermal conductivity and modulus of elasticity. Titanium alloys are used in variety of application in aerospace, bio-medical and automotive industries. Researchers and practicing engineers are working towards finding optimum cutting conditions for machining titanium alloy with an objective of improving the tool life. Cutting tools such as tungsten carbide and cubic boron nitride are found to be suitable for machining titanium alloys. Usually titanium alloys are machined in CNC machine tools with higher cutting velocities. Higher cutting velocity found to be improving the cutting life of the tool compared with conventional cutting range. In an automated environment, it is important to have tool condition monitoring system so that in real-time condition of the tool can be monitored. This type of system will give warning to the operators to change the tool or to stop the machine if the tool condition becomes poor or worn-out. There by any wastage in terms material, time can be saved.

In this work, $\mathrm{AE}$ and Vibration data were collected during high speed milling of titanium alloy. Cutting conditions are 
chosen based on maximizing the tool life. Preliminary experiments were carried out to find optimum process parameters for obtaining maximum tool life condition. Depth of cut and feed rate are fixed as $0.3 \mathrm{~mm}$ and $300 \mathrm{~mm}$ per min respectively. Cutting speed is varied between $150 \mathrm{~m} / \mathrm{min}$ to $350 \mathrm{~m} / \mathrm{min}$ in the interval of $25 \mathrm{~m} / \mathrm{min}$. A tungsten carbide $4 \mathrm{~mm}$ end-mill cutter is used in this study. For each experiment, from good condition of the tool to the worn-out condition, tool flank wear is monitored. The rationale behind considering the flank wear is that during machining of titanium and its alloys tool failures are mainly due to the flank wear. Surface roughness obtained in the work piece surface is also recorded. A cutting speed of $225 \mathrm{~mm} / \mathrm{min}$ is found to be providing maximum tool life.

Three tool conditions such as good, worn-out and intermediate conditions were chosen based on the tool wear profile. Tool wear profile is plotted based on the flank wear. For plotting the tool wear profile surface roughness in the work piece is monitored at fixed time interval until the cutting tool become worn-out. Using the tool wear profile, tool conditions are defined as good, intermediate and worn-out based on the surface roughness value. The tool wear profile indicating the tool conditions ( $\mathrm{a}, \mathrm{b}$ and $\mathrm{c}$ ) is shown in the Figure 11. Up to the point ' $a$ ' tool is defined as good condition based on the flank wear of the tool. From the point ' $a-b$ ' is intermediate condition and 'b-c' the tool wear progresses rapidly and fails at point 'c'.

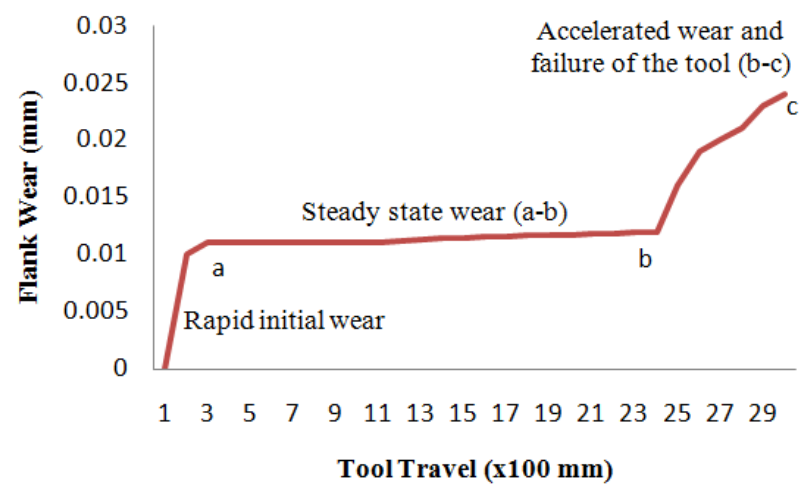

Figure 11. Tool wear profile

Under optimum condition, machining is carried out for full cycle starting from the good tool condition. Machining is carried out until the tool become worn-out. For the entire cycle $\mathrm{AE}$ and vibration signatures were acquired and signal processing is carried out to identify the tool conditions. Raw $\mathrm{AE}$ and vibration signals are processed in time-domain, frequency domain and time -frequency domain. Features are extracted from the $\mathrm{AE}$ and vibration signature and machine learning algorithms are used for tool condition classification.

$\mathrm{AE}$ and Vibration (time series) data was collected for the entire machining cycle from good tool condition to the Wornout condition. Optimum cutting parameters are chosen for the machining. For each condition of the tool, 28 data points were used for the time domain data analysis using vibration signature (i.e a total of 84 data points) and for AE signature, a total of 256 data points were used for each tool condition (i.e a total of 768 data points). In frequency domain analysis, 45 data points for each tool condition is chosen for vibration data (i.e a total of 135 data points) and 100 data points for each tool condition is chosen for AE data (i.e a total of 300 data points). In wavelet domain, 45 data points for each tool condition is chosen (i.e a total of 135 data points) for vibration data and for $\mathrm{AE}$ signature in 100 data points for each tool condition is chosen (i.e a total of 300 data points).

For time-domain fusion of $\mathrm{AE}$ and Vibration data, a total of 84 data points were used for the classification (i.e 28 data points for each of the tool condition). For the future level fusion in frequency domain and wavelet domain, 135 data points were used (i.e 45 data points for each of the tool condition).

\section{MACHINE LEARNING ALGORITHMS FOR TOOL CONDITION CLASSIFICATION}

Machine learning (Carbonell et al., 1993) is a process of both 'Learning' (Learning to Label) and 'Labeling' (Identifying the object as a member of a class to which it belongs). In this study, machine learning classifiers are used to identify the tool wear status from the signal pattern during machining. One of the important reasons for adopting machine learning classifier is to achieve automatic tool condition monitoring system. The tool condition identification using machine learning classification has three phases namely featureextraction, feature-selection / reduction and featureclassification. In feature-extraction phase, statistical, histogram, and wavelet features are extracted from the vibration and acoustic emission signal induced during the machining process.

In the feature selection phase, features which have relevant information about the tool conditions are selected. Feature selection process is also called as dimensionality reduction. Dimensionality reduction techniques will reduce the computation time by eliminating the redundant or unwanted data and also help to improve the classification efficiency of the machine learning algorithm. Techniques such as Principal Component Analysis (PCA), Decision Tree (DT) and Independent Component Analysis (ICA) are used for feature selection.

Machine learning classifiers are used to classify the features based on the tool conditions. Classification algorithms are initially trained with features whose tool conditions are known. After training, the classifier is used to predict the tool conditions for the features whose tool conditions are not known. Various machine learning classifiers are tried by the researches for tool condition classification. 
A comprehensive review on application of ANN was made by Sick (2002) for decision making. Shi and Gindy (2007) proposed a least square SVM model for tool wear prediction. Elangovan et al. (2010, 2011(a-b)) used Bayes classifier, SVM, and decision tress for classification of single point cutting tool conditions using vibration signals. Wang et al. (2011) proposed the tool condition prediction model using SVM. Decision tree and ANN were used for end mill tool condition monitoring by Krishnakumar et al. (2015). Zhang et al., (2016) proposed a neuro-fuzzy model to predict the tool wear. Krishnakumar et al. (2018) proposed a wavelet based tool condition classification using vibration and $\mathrm{AE}$ data. Machine learning classifiers are used in their study to predict the tool conditions. In this work C 4.5 decision tree, two variants of SVM algorithms namely C-SVC and nu-SVC, Naïve Bayes and artificial neural networks are considered as classifiers for tool condition classification.

In this study, machine learning classifiers such as Decision Tree, Naïve Bays and Neural Network are implemented in the Weka open-source platform (https: //www. cs. waikato. ac. nz ). SVM algorithms are implemented using 'DTREG predictive modeling software' (https://www.dtreg.com/).

\subsection{Decision trees}

Decision trees are popular supervised learning algorithm and used for data classification type of problems. The decision tree split the features in to different diverse groups using criterions such as gini index, information gain strategy, chisquare value and entropy. A decision tree algorithm C4.5 proposed by Quinlan (1993) is one of the commonly used algorithm to generate decision tree. In the process of generating decision trees, the training sets with attributes are recursively partitioned until all the data in a partition have the similar class. For the entire training set, the decision tree will have the single root node for the entire training set. A new node is added to the decision tree for every division. Splitting criterion in C4.5 algorithm is based on the entropy.

The training set, ' $\mathrm{S}$ ' for $\mathrm{C} 4.5$ consisting of known classified samples 's1, s2,... si'. The sample 'si' is a 'p' dimensional vector. The feature of the sample and its corresponding class is represented as 'si'. At each node, the algorithm selects the feature that most efficiently divides the data into one class or the other based on the entropy. The decision will be made based on the feature with highest entropy (information gain). Let $|\mathrm{D}|$ is the total number of features and $\left|\mathrm{D}_{\mathrm{i}}\right|$ is the number of features classified as class ' $i$ '. The probability ( $\mathrm{p}_{\mathrm{i}}$ ) of no. of features classified in the ith class is expressed as $\left|\mathrm{D}_{\mathrm{i}}\right| /|\mathrm{D}|$. The entropy is computed using the equation (1).

Entropy, $\mathrm{D}=-\sum_{\mathrm{i}=1}^{\mathrm{k}} \mathrm{p}_{\mathrm{i}} \log \mathrm{p}_{\mathrm{i}}$

C4.5 algorithm for building decision trees is implemented in Weka as classifier called J48. Tenfold cross validation has been used for evaluation, i.e. $90 \%$ of the data is used for training and $10 \%$ of data is used for testing. The confidence factor for pruning is set to 0.25 .

\subsection{Support vector machines}

Support vector machines (SVM) are supervised learning algorithm, proposed by Cortes and Vapnik (1995) based on statistical learning theory. In a two class classification problem, input data corresponds to the two classes is shown in the Figure 12. SVM tries to find the hyper plane, which separates the data belongs to each class. The main objective in SVM is to maximize the 'margin' where by clear distinction between the classes can be made. The margin is separated by bounding planes. The data points which lie on the bounding planes are called as support vectors. There are two parameters in SVM used to quantify the margin are a) the orientation parameter (w) and b) location parameter which is relative to origin separating the hyper plane $(\gamma)$. The mathematical forms of hyper plane and bounding planes are shown in Figure 12. The margin is defined in the equation (2).

Margin $=\frac{-\gamma-1}{\sqrt{\mathrm{w}_{1}^{2}+\mathrm{w}_{2}^{2}}}-\frac{-\gamma+1}{\sqrt{\mathrm{w}_{1}^{2}+\mathrm{w}_{2}^{2}}}$

The classification error is quantified based on the distance of the data points from the bounding planes for every class. For example, the distances between the data points belong to a class say, $\mathrm{y}_{1}, \mathrm{y}_{2}, \ldots \mathrm{y}_{\mathrm{n}}$. The total error is computed using the Equation (3).

The classification error $=\sum_{i=1}^{n} y_{i}$

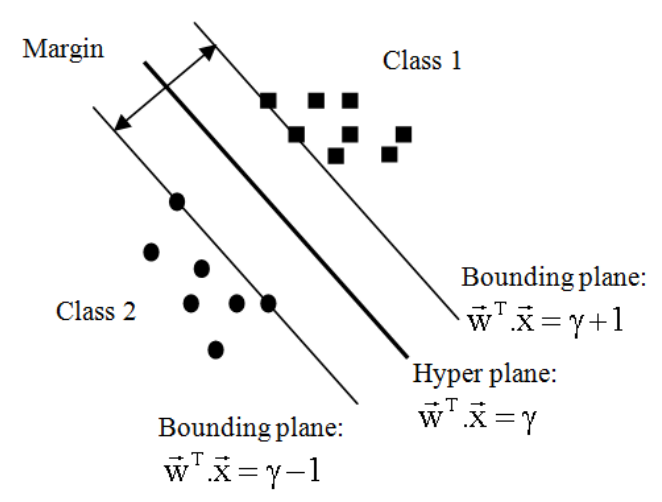

Figure 12. SVM algorithm - 2 class problem representation

In SVM, both the objectives i.e., maximizing the margin and minimizing the error has to be considered for arriving the maximum classification efficiency. In SVM, the problem has to be formulated to find the optimum hyper plane which classifies the data into two classes in a two class problem. The data belong to the class 1 and 2 will have to satisfy the equations (4) and (5) respectively. Combining equations (4) 
and (5) a decision function is formed as shown in equation (6). Data fitting to a particular class is arrived based on the definiteness of the objective function. The data is set to the class 2 , if the objective function value is positive. If the function value is negative, the data is set to the class 1 .

$$
\begin{aligned}
& \text { Data belong to class } 1: \overrightarrow{\mathrm{w}}^{\mathrm{T}} \cdot \overrightarrow{\mathrm{x}} \leq \gamma-1 \\
& \text { Data belong to class } 2: \overrightarrow{\mathrm{w}}^{\mathrm{T}} \cdot \overrightarrow{\mathrm{x}} \geq \gamma+1 \\
& \text { Decision function } \mathrm{f}(\mathrm{x})=\operatorname{sign}\left(\overrightarrow{\mathrm{w}}^{\mathrm{T}} \cdot \overrightarrow{\mathrm{x}}-\gamma\right)
\end{aligned}
$$

For improving the efficiency of classification, kernel functions are used to transform the data into higher dimensional space. In higher dimensional space linear separation is carried out. Kernel functions like linear, polynomial, sigmoid, Radial Basis Function (RBF), etc, are used to convert the data from linearly non-separable domain to a linearly-separable domain.

Two variants of SVM such as C-SVC and nu-SVC are popular in data classification. The parameters ' $\mathrm{C}$ ' and 'nu' are used to implement penalty for mis-classification. By properly tuning these parameters classification accuracy of the algorithm may be improved. The parameter ' $C$ ' usually in the range ' 0 ' and 'infinity'. The parameter 'nu' operates between ' 0 ' and ' 1 '. A ' $\mathrm{V}$ ' fold cross validation is performed in this study. In this study all the results were taken by considering $\mathrm{V}=10$. The classification efficiency of c-SVC and nu-SVC for various kernel functions are evaluated. SVM variants, c-SVC and nu-SVC are implemented in 'DTREG' predictive modeling software.

\subsection{Naive Bayes}

Naive Bayes is a probabilistic classifier working based on Bayes theorem (Russell et al., 2003). It is supervised learning approach. The features are represented as a vector, $\mathrm{x}=\mathrm{x}_{1}, \mathrm{x}_{2}$, $\ldots, \mathrm{x}_{\mathrm{n}}$. Probabilities are assigned to features belonging to the class $\mathrm{C}_{\mathrm{k}}$ such as $\mathrm{p}\left(\mathrm{C}_{\mathrm{k}} \mid \mathrm{x}_{1}, \mathrm{x}_{2}, \cdots, \mathrm{x}_{\mathrm{n}}\right)$. The conditional probability for a feature belongs to a particular class can be express as given in the Equation (7).

$$
\mathrm{p}\left(\mathrm{C}_{\mathrm{k}} \mid \mathrm{x}\right)=\frac{\mathrm{p}\left(\mathrm{C}_{\mathrm{k}}\right) \mathrm{p}\left(\mathrm{C}_{\mathrm{k}} \mid \mathrm{x}\right)}{\mathrm{p}(\mathrm{x})}
$$

A 10 fold cross validation is used in this study for simulating the Naive Bayes algorithm implemented in the open source Weka suite. Cross validation is performed to describe a dataset to "test" the model in the training stage itself. The cross validation process divides the sample dataset into subsets. It performs the analysis on one set (training set), and validate the analysis on the other set (testing set). To reduce variability, multiple times of cross-validations are performed.

\subsection{Artificial Neural Network}

Artificial Neural Network (ANN) is a machine learning classifier that models human intelligence in decision making (Rumelhart et al., 1988). The network consists of an input layer, output layer and hidden layers. Input, output and hidden layers consisting of neurons which are interconnected in parallel. The network is trained using the features obtained from the $\mathrm{AE}$ and vibration signals considered in this study for tool condition classification.

A multi-layer perceptron with feed forward back propagation Neural Network model available in Weka suit is selected in this study for classifying the vibration feature data according to the tool condition. In this study, the inputs to ANN are the dominant features selected by $\mathrm{C} 4.5$ algorithm. For the Vibration signals, the input features are standard error, kurtosis and median. Neurons are given with sigmoid activation functions. The output layer of the neural net contains the neurons representing the stages of tool condition such as good tool, tool at mid of it life and worn out tool. One hidden layer with 10 hidden neurons is used for training and testing of ANN for both vibration and AE based features. No. of hidden layers and no. of neurons in the hidden layers are arrived by conducting trial experiments.

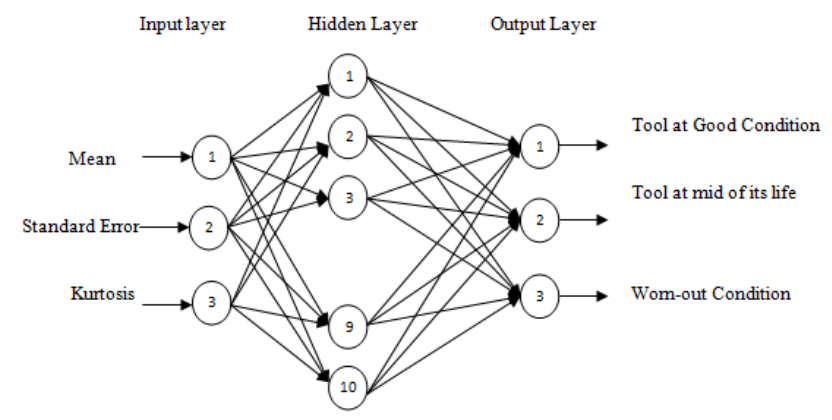

Figure 13. ANN Architecture for vibration data

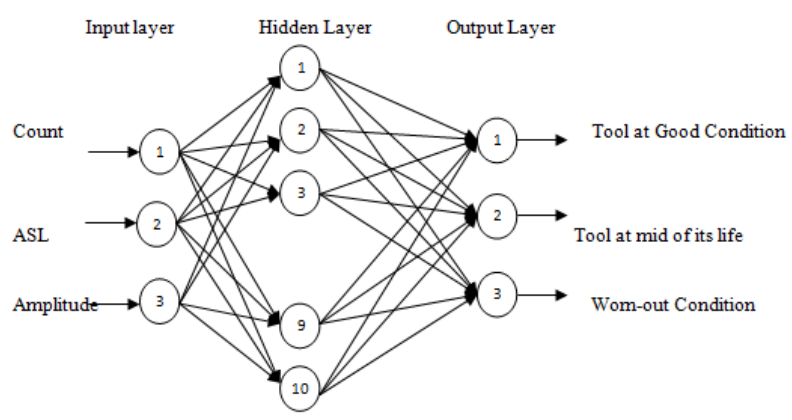

Figure 14. ANN Architecture for AE data

A 10 fold cross validation is used in this study for testing and simulating the neural net. Cross validation is performed to describe a dataset to "test" the model in the training stage itself. The cross validation process divides the data set 
into sub-sets. It performs the analysis on one set (training set), and validate the analysis on the other set (testing set). To reduce variability, multiple times of cross-validations are performed. The architecture of the ANN for vibration based studies is shown in the Figure 13. For AE based features the architecture is shown in Figure 14.

\section{FEATURE LEVEL FUSION OF AE AND VIBRATION SIGNALS}

In this work, feature selection is followed by data fusion as indicated in the Figure 15. All the features of $\mathrm{AE}$ and vibration are fed into common data base (Fusion matrix). Separate matrix is created for time-domain, frequency domain and wavelet domain. The dominating features are selected using the decision tree algorithm. The dominating features of $\mathrm{AE}$ and Vibration are fed into machine learning classifiers. In this work a C4.5 decision tree algorithm is used for feature reduction. Dominant features contain rich information about the tool conditions. The feature reduction will help in reducing the time complexity and classification accuracy of the algorithm. The selected features are used to train the machine learning algorithm for tool condition classification. The feature level fusion approach is shown in the Figure 16. This data fusion is carried out in time domain, frequency domain and wavelet domain.

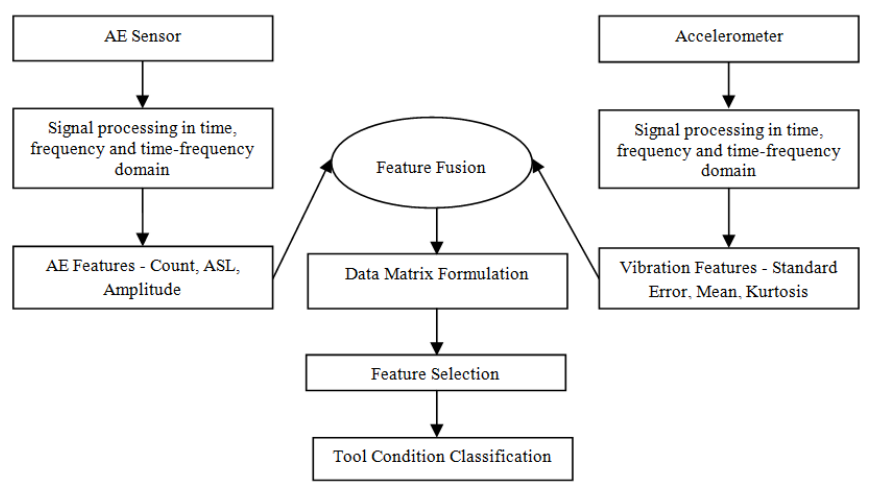

Figure 15. Data fusion methodology

The acoustic emission statistical features that are fed into the feature fusion matrix are count, average signal level and amplitude. Count refers to the number of times the signal crosses the threshold. Based on the magnitude of the $\mathrm{AE}$ event and the characteristics of the material, one hit may produce one or many counts. Average Signal Level (ASL) is the rectified, time averaged $\mathrm{AE}$ logarithmic signal, measured on the AE amplitude logarithmic scale. Amplitude is the maximum value of the signal measured in volts, which is used to find the traceability of the signature. From the vibration signal, features that are fed to the data fusion matrix are standard error, mean and kurtosis. Standard error is the measure of spread. Mean is the average of ' $n$ ' number of vibration data points of the signal and kurtosis is the measure of peakedness of the signal.

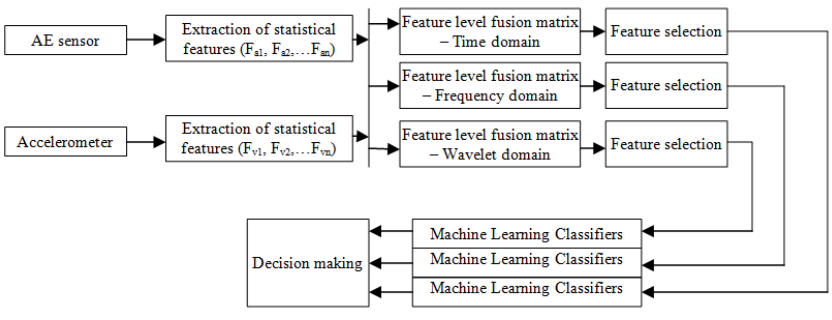

Figure 16. Feature level fusion of $\mathrm{AE}$ and vibration signal features

\subsection{Feature level fusion in time-domain}

The statistical features from acoustic emission and vibration signals are fed into C 4.5 decision tree algorithm. The standard error from vibration signal and ASL from the acoustic emission signal are at the root nodes of the decision tree. These are the dominating features which have higher information content compared to other features from vibration and acoustic emission signals considered in this study. The decision tree is shown in Figure 17. Standard Error from vibration data and ASL from AE data are chosen as dominant features. These features are provided as an input to classifiers for training and testing.

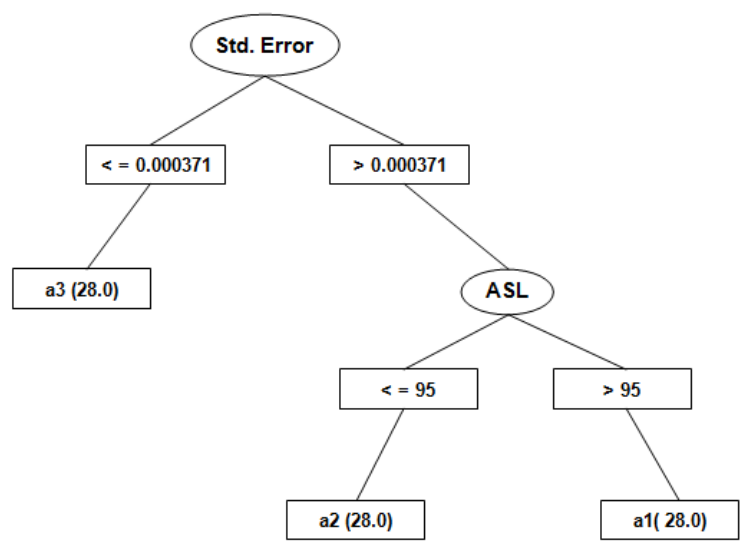

Figure 17. Decision tree of fused data in time domain

\subsection{Feature level fusion in frequency domain}

The time domain signals are converted in to frequency domain using Fourier transforms. The statistical features were extracted from AE and Vibration signals in frequency domain. They are sum, mean, median, minimum, maximum, standard deviation, variance, kurtosis and skewness from both vibration and acoustic emission signals. The statistical features of both the signals in frequency domain were given as an input to Decision Tree to identify the best features for classification. From the decision tree shown in Figure 18, it is found that maximum, skewness, standard deviation from vibration signal and the standard deviation from $\mathrm{AE}$ signals are the best statistical features in frequency domain to classify the tool condition. 


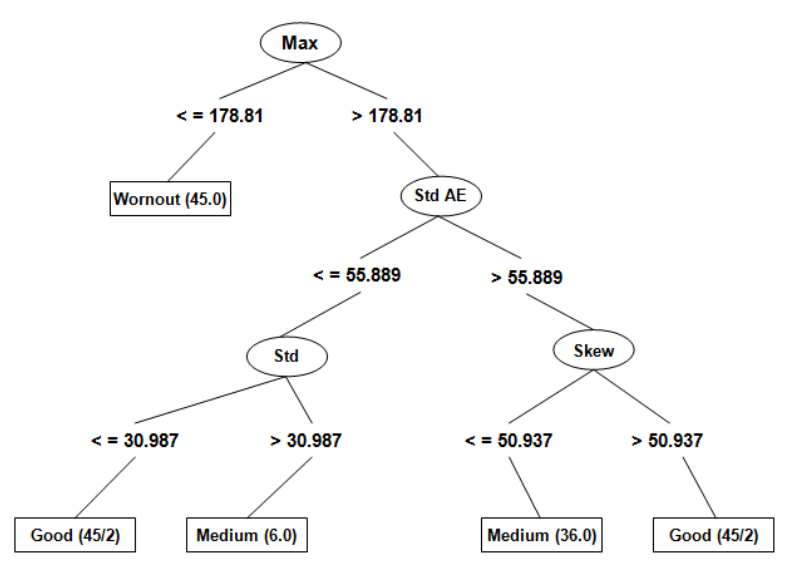

Figure 18. Decision tree of fused data in frequency domain

\subsection{Feature level fusion in time-frequency domain (Wavelet domain)}

The wavelet coefficients were extracted from the vibration and AE signals to obtain the time frequency resolution of the signal using wavelet transforms. The extracted wavelets are Haar, biorthogonal (bior 3.9, bior 4.4 and bior 5.5), Daubechies (db11, db12, db13 and $\mathrm{db} 14$ ) and reverse biorthogonal (rbio 4.4, rbio 5.5 and rbio 6.8). From the extracted wavelets best performing wavelets are identified. The best performing wavelets identified are Haar wavelet from vibration signature and the bior 4.4 wavelet from acoustic emission signals. The wavelet coefficients are fused together to form a single data set. The fused data set is used for tool condition classification. Decision tree generated for the fused data in wavelet domain is shown in the Figure 19.

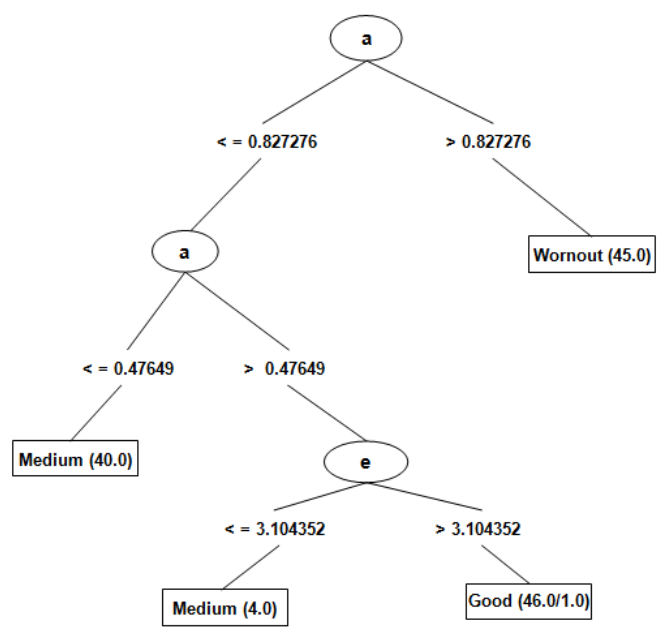

Figure 19. Decision tree for fused data in wavelet domain

The root nodes in the decision tree indicate the dominating coefficients in tool condition classification at different levels of decomposition. In Figure ' $a$ ' and ' $e$ ' indicates the first and fifth level decompositions of vibration signal.

\section{TOOL CONDITION CLASSIFICATION}

The selected features using decision tree are standard error from vibration and ASL from acoustic emission signals. These features are used as input in the decision tree algorithm, Naive Bayes, Support vector machines and artificial neural network to identify the tool condition. A 10 fold cross validation method was used in simulating the machine learning classifiers. The idea of cross validation is to define a dataset to "test" the model in the training phase itself. The cross validation involves dividing the sample dataset into subsets, performing the analysis on one subset (training set), and validating the analysis on the other subset (testing set). To reduce variability, multiple times of cross-validation were performed using different divisions, and the validation results are averaged over the number of times.

The performances of the classifiers are studied using the confusion matrix. Confusion matrix is a table, which describes the performance of the classifier. A typical confusion matrix for a 3-class problem is shown in the Table 1. From the confusion matrix classifier performances such as overall classification efficiency (accuracy), error rate and kappa statistics can be obtained.

In this study we have computed overall accuracy of the classifiers for the performance evaluation of the classifiers. The performance of a classifier is depends on the counts of test records correctly and incorrectly predicted by the model. These counts are tabulated in the form of confusion matrix.

The confusion matrix for a 3-Class problem is shown in Table 1. Each entry 'Fij' in this table denotes the number of records from class 'i' predicted to be of the class ' $j$ '. For instance, 'Fba' is the number of records from class ' $\mathrm{B}$ ' incorrectly predicted as class ' $\mathrm{A}$ '. The total number of correct predictions made by the classifier is ' $F_{a a}+F_{b b}+F_{c c}$ '. The total number of incorrect predictions made by the classifier is ' $\mathrm{F}_{\mathrm{ab}}+\mathrm{F}_{\mathrm{ac}}+\mathrm{F}_{\mathrm{ba}}+\mathrm{F}_{\mathrm{bc}}+\mathrm{F}_{\mathrm{ca}}+\mathrm{F}_{\mathrm{cb}}$ '.

Table 1. Confusion matrix for a 3-class problem

\begin{tabular}{|c|c|c|c|c|}
\hline \multicolumn{2}{|c|}{} & \multicolumn{3}{c|}{ Predicted Class } \\
\cline { 3 - 5 } \multicolumn{2}{|c|}{} & Class - A & Class - B & Class - C \\
\hline \multirow{3}{*}{ Actual Class } & Class - A & $\mathrm{F}_{\mathrm{aa}}$ & $\mathrm{F}_{\mathrm{ab}}$ & $\mathrm{F}_{\mathrm{ac}}$ \\
\cline { 2 - 5 } & Class - B & $\mathrm{F}_{\mathrm{ba}}$ & $\mathrm{F}_{\mathrm{bb}}$ & $\mathrm{F}_{\mathrm{bc}}$ \\
\cline { 2 - 5 } & Class - C & $\mathrm{F}_{\mathrm{ca}}$ & $\mathrm{F}_{\mathrm{cb}}$ & $\mathrm{F}_{\mathrm{cc}}$ \\
\hline
\end{tabular}

The confusion matrix present the details needed to decide how well a classification model performs. Summarizing this detail with a single number would be more convenient to compare the performance of different algorithms. This can be done using the performance metric such as accuracy and error rate. 
Classification Efficiency,\%

$=\frac{\text { Number of correct predictions }}{\text { Total number of predictions }} \times 100$

$$
=\frac{\mathrm{F}_{\mathrm{aa}}+\mathrm{F}_{\mathrm{bb}}+\mathrm{F}_{\mathrm{cc}}}{\mathrm{F}_{\mathrm{aa}}+\mathrm{F}_{\mathrm{ab}}+\mathrm{F}_{\mathrm{ac}}+\mathrm{F}_{\mathrm{ba}}+\mathrm{F}_{\mathrm{bb}}+\mathrm{F}_{\mathrm{bc}}+\mathrm{F}_{\mathrm{ca}}+\mathrm{F}_{\mathrm{cb}}+\mathrm{F}_{\mathrm{cc}}} \times 100
$$

$=\frac{\text { Number of incorrect predictions }}{\text { Total number of predictions }} \times 100$

$$
=\frac{\mathrm{F}_{\mathrm{ab}}+\mathrm{F}_{\mathrm{ac}}+\mathrm{F}_{\mathrm{ba}}+\mathrm{F}_{\mathrm{bc}}+\mathrm{F}_{\mathrm{ca}}+\mathrm{F}_{\mathrm{cb}}}{\mathrm{F}_{\mathrm{aa}}+\mathrm{F}_{\mathrm{ab}}+\mathrm{F}_{\mathrm{ac}}+\mathrm{F}_{\mathrm{ba}}+\mathrm{F}_{\mathrm{bb}}+\mathrm{F}_{\mathrm{bc}}+\mathrm{F}_{\mathrm{ca}}+\mathrm{F}_{\mathrm{cb}}+\mathrm{F}_{\mathrm{cc}}} \times 100
$$

\subsection{SVM variants}

Two variants of SVM models such as c-Support Vector Classifier (c-SVC), nu-Support Vector Classifier (nu-SVC) were tried with different kernel functions. In nu-SVM a parameter ' $\mu$ ' is introduced with an objective of optimizing the number of support vectors to reduce the training errors. The classification efficiency of c-SVC and nu-SVC for various kernel functions are presented in the Table 2 and 3 for the vibration and $\mathrm{AE}$ data respectively. Comparisons were made using the kernel functions namely linear, polynomial, sigmoid and Radial Basic Function (RBS).

Table 2: Classification efficiency of c-SVC and nu-SVC with different kernel functions (Vibration data)

\begin{tabular}{|l|l|l|}
\hline \multirow{2}{*}{ Kemel function } & \multicolumn{2}{|l|}{ Classification Efficiency, \% } \\
\cline { 2 - 3 } & c-SVC & nu-SVC \\
\hline Linear & 96.55 & 93.10 \\
\hline Polynomial (degree 3) & 96.55 & 96.55 \\
\hline Sigmoid & 96.55 & 94.23 \\
\hline Radial Basis Function & 96.55 & 96.55 \\
\hline
\end{tabular}

Table 3: Classification efficiency of c-SVC and nu-SVC with different kernel functions (AE data)

\begin{tabular}{|l|l|l|}
\hline \multirow{2}{*}{ Kemel function } & \multicolumn{2}{|l|}{ Classification Efficiency, \% } \\
\cline { 2 - 3 } & c-SVC & nu-SVC \\
\hline Linear & 98.31 & 69.92 \\
\hline Polynomial (degree 3) & 99.48 & 78.9 \\
\hline Sigmoid & 97.00 & 79.17 \\
\hline Radial Basis Function & 99.48 & 66.40 \\
\hline
\end{tabular}

The results shows c-SVC with radial Basic Function (RBF) is performing better in terms of classification efficiency for vibration and $\mathrm{AE}$ data for the test cases considered in this study. SVM classifier referred in this study is c-SVC variant with Radial Basis Function (RBS) Kernel function.

\subsection{Confusion matrix of the non-fused data}

Confusion matrix of the non-fused data of vibration and $\mathrm{AE}$ signatures in time-domain, and frequency-domain are shown in Table 4, 5, 6 and 7. The table also indicates the classification efficiency of respective classifiers.

Table 4: Confusion matrix for non-fused data in time

\begin{tabular}{|c|c|c|c|c|}
\hline \multicolumn{5}{|c|}{ Decision Tree Classifier } \\
\hline $\begin{array}{c}\text { Good Tool } \\
\text { Class A }\end{array}$ & $\begin{array}{c}\text { Intermediate } \\
\text { Class B }\end{array}$ & $\begin{array}{l}\text { Wom-out } \\
\text { Class C }\end{array}$ & Tool Condition & $\begin{array}{l}\text { Classification } \\
\text { Efficiency, \% }\end{array}$ \\
\hline 26 & 3 & 0 & Good Tool & \multirow{3}{*}{94.3} \\
\hline 2 & 27 & 0 & Intermediate & \\
\hline 0 & 0 & 29 & Wom-out & \\
\hline \multicolumn{5}{|c|}{ Naîve Bayes Classifier } \\
\hline 28 & 1 & 0 & Good Tool & \multirow{3}{*}{96.55} \\
\hline 2 & 27 & 0 & Intermediate & \\
\hline 0 & 0 & 29 & Wom-out & \\
\hline \multicolumn{5}{|c|}{ SVM Classifier } \\
\hline 27 & 2 & 0 & Good Tool & \multirow{3}{*}{96.55} \\
\hline 1 & 28 & 0 & Intermediate & \\
\hline 0 & 0 & 29 & Worn-out & \\
\hline \multicolumn{5}{|c|}{ ANN Classifier } \\
\hline 29 & 0 & 0 & Good Tool & \multirow{3}{*}{97.5} \\
\hline 0 & 27 & 2 & Intermediate & \\
\hline 0 & 2 & 27 & Wom-out & \\
\hline
\end{tabular}
domain for vibration data

Table 5: Confusion matrix for non-fused data in time

\begin{tabular}{|c|c|c|c|c|}
\hline \multicolumn{5}{|c|}{ Decision Tree Classifier } \\
\hline $\begin{array}{c}\text { Good Tool } \\
\text { Class A }\end{array}$ & $\begin{array}{c}\text { Intermediate } \\
\text { Class B } \\
\end{array}$ & $\begin{array}{l}\text { Wom-out } \\
\text { Class C }\end{array}$ & Tool Condition & $\begin{array}{l}\text { Classification } \\
\text { Efficiency, \% }\end{array}$ \\
\hline 247 & 9 & 0 & Good Tool & \multirow{3}{*}{98.69} \\
\hline 0 & 256 & 0 & Intermediate & \\
\hline 0 & 1 & 255 & Wom-out & \\
\hline \multicolumn{5}{|c|}{ Naïve Bayes Classifier } \\
\hline 84 & 148 & 0 & Good Tool & \multirow{3}{*}{75.91} \\
\hline 6 & 243 & 0 & Intermediate & \\
\hline 0 & 0 & 255 & Worm-out & \\
\hline \multicolumn{5}{|c|}{ SVM Classifier } \\
\hline 253 & 3 & 0 & Good Tool & \multirow{3}{*}{99.48} \\
\hline 1 & 255 & 0 & Intermediate & \\
\hline 0 & 0 & 256 & Worm-out & \\
\hline \multicolumn{5}{|c|}{ ANN Classifier } \\
\hline 256 & 1 & 0 & Good Tool & \multirow{3}{*}{97.4} \\
\hline 0 & 245 & 9 & Intermediate & \\
\hline 0 & 10 & 247 & Worn-out & \\
\hline
\end{tabular}
domain for $\mathrm{AE}$ data

Table 6: Confusion matrix for non-fused data in frequency

\begin{tabular}{|c|c|c|c|c|}
\hline \multicolumn{5}{|c|}{ Decision Tree Classifier } \\
\hline $\begin{array}{c}\text { Good Tool } \\
\text { Class A }\end{array}$ & $\begin{array}{c}\text { Intermediate } \\
\text { Class B }\end{array}$ & $\begin{array}{l}\text { Worm-out } \\
\text { Class C }\end{array}$ & Tool Condition & $\begin{array}{l}\text { Classification } \\
\text { Efficiency, \% }\end{array}$ \\
\hline 39 & 6 & 0 & Good Tool & \multirow{3}{*}{92.59} \\
\hline 3 & 42 & 0 & Intermediate & \\
\hline 1 & 0 & 44 & Worm-out & \\
\hline \multicolumn{5}{|c|}{ Naîve Bayes Classifier } \\
\hline 40 & 5 & 0 & Good Tool & \multirow{3}{*}{93.33} \\
\hline 3 & 42 & 0 & Intermediate & \\
\hline 1 & 0 & 44 & Wom-out & \\
\hline \multicolumn{5}{|c|}{ SVM Classifier } \\
\hline 40 & 5 & 0 & Good Tool & \multirow{3}{*}{91.11} \\
\hline 4 & 41 & 0 & Intermediate & \\
\hline 3 & 0 & 42 & Wom-out & \\
\hline \multicolumn{5}{|c|}{ ANN Classifier } \\
\hline 40 & 3 & 2 & Good Tool & \multirow{3}{*}{95.6} \\
\hline 0 & 44 & 1 & Intermediate & \\
\hline 0 & 0 & 45 & Wom-out & \\
\hline
\end{tabular}
domain for vibration data 
Table 7: Confusion matrix for non-fused data in frequency domain for $\mathrm{AE}$ data

\begin{tabular}{|c|c|c|c|c|}
\hline \multicolumn{5}{|c|}{ Decision Tree Classifier } \\
\hline $\begin{array}{l}\text { Good Tool } \\
\text { Class A }\end{array}$ & $\begin{array}{c}\text { Intermediate } \\
\text { Class B }\end{array}$ & $\begin{array}{l}\text { Worm-out } \\
\text { Class C }\end{array}$ & Tool Condition & $\begin{array}{l}\text { Classification } \\
\text { Efficiency, \% }\end{array}$ \\
\hline 80 & 15 & 5 & Good Tool & \multirow{3}{*}{80} \\
\hline 23 & 70 & 7 & Intermediate & \\
\hline 2 & 8 & 90 & Wom-out & \\
\hline \multicolumn{5}{|c|}{ Naïve Bayes Classifier } \\
\hline 100 & 0 & 0 & Good Tool & \multirow{3}{*}{73} \\
\hline 0 & 61 & 39 & Intermediate & \\
\hline 0 & 42 & 58 & Worm-out & \\
\hline \multicolumn{5}{|c|}{ SVM Classifier } \\
\hline 81 & 14 & 5 & Good Tool & \multirow{3}{*}{83} \\
\hline 22 & 75 & 3 & Intermediate & \\
\hline 5 & 2 & 93 & Wom-out & \\
\hline \multicolumn{5}{|c|}{ ANN Classifier } \\
\hline 100 & 0 & 0 & Good Tool & \multirow{3}{*}{89.7} \\
\hline 17 & 63 & 4 & Intermediate & \\
\hline 3 & 2 & 95 & Wom-out & \\
\hline
\end{tabular}

\subsection{Confusion matrix of the fused data}

Confusion matrix of the fused data in time-domain, frequency-domain and time-frequency (wavelet) domain are shown in the Table 8, 9 and 10. Confusion matrix provides information related to individual classes and over all classification efficiency of the algorithm. For an example, in the case of frequency domain data, as shown in Table 7, a Decision Tree classifier mis-classifies five data points belong to class 'a' (Good condition) as class 'b' (Intermediate condition). Five data points belong to class ' $b$ ' (Intermediate condition) were misclassified as class ' $a$ ' (Good condition) and 1 data points belongs to class ' $c$ ' (Worn out condition) is misclassified as class 'a' (Good condition). Out of 135 data points presented to the classifier, 11 instances are misclassified and 124 instances are correctly classified. The overall classification efficiency of the Decision tree algorithm is $91.85 \%$ and the error rate is $8.15 \%$. Confusion matrix is used as an effective tool to study the performance of machine learning classifiers.

Table 8: Confusion matrix of the fused data in time domain

\begin{tabular}{|c|c|c|c|c|}
\hline \multicolumn{5}{|c|}{ Decision Tree classifier } \\
\hline $\begin{array}{c}\text { Good tool } \\
\text { Class A }\end{array}$ & $\begin{array}{c}\text { Intermediate } \\
\text { Class B }\end{array}$ & $\begin{array}{l}\text { Worn-out } \\
\text { Class C }\end{array}$ & Tool condition & $\begin{array}{l}\text { Classification } \\
\text { efficiency, \% }\end{array}$ \\
\hline 27 & 1 & 0 & Good Tool & \multirow{3}{*}{97.62} \\
\hline 1 & 27 & 0 & Intermediate & \\
\hline 0 & \begin{tabular}{|l|}
0 \\
\end{tabular} & 28 & Worn-out & \\
\hline \multicolumn{5}{|c|}{ Naive Bayes classifier } \\
\hline 28 & $\begin{array}{l}0 \\
\end{array}$ & 0 & Good Tool & \multirow{3}{*}{100} \\
\hline 0 & 28 & 0 & Intermediate & \\
\hline 0 & 0 & 28 & Worn-out & \\
\hline \multicolumn{5}{|c|}{ SVM classifier } \\
\hline 28 & 0 & 0 & Good Tool & \multirow{3}{*}{100} \\
\hline 0 & 28 & 0 & Intermediate & \\
\hline 0 & 0 & 28 & Worn-out & \\
\hline \multicolumn{5}{|c|}{ ANN classifier } \\
\hline 28 & 0 & 0 & Good Tool & \multirow{3}{*}{100} \\
\hline 0 & 28 & 0 & Intermediate & \\
\hline 0 & 0 & 28 & Worn-out & \\
\hline
\end{tabular}

Table 9: Confusion matrix of the fused data in frequency domain

\begin{tabular}{|c|c|c|c|c|}
\hline \multicolumn{5}{|c|}{ Decision Tree classifier } \\
\hline $\begin{array}{l}\text { Good tool } \\
\text { Class A }\end{array}$ & $\begin{array}{c}\text { Intermediate } \\
\text { Class B }\end{array}$ & $\begin{array}{l}\text { Worn-out } \\
\text { Class C }\end{array}$ & Tool condition & $\begin{array}{l}\text { Classification } \\
\text { efficiency, \% }\end{array}$ \\
\hline 40 & 5 & 0 & Good Tool & \multirow{3}{*}{91.85} \\
\hline 5 & 40 & 0 & Intermediate & \\
\hline 1 & 0 & 44 & Worn-out & \\
\hline \multicolumn{5}{|c|}{ Naive Bayes classifier } \\
\hline 44 & 1 & 0 & Good Tool & \multirow{3}{*}{96.29} \\
\hline 4 & 41 & 0 & Intermediate & \\
\hline 0 & 0 & 45 & Worn-out & \\
\hline \multicolumn{5}{|c|}{ SVM classifier } \\
\hline 44 & 1 & 0 & Good Tool & \multirow{3}{*}{96.29} \\
\hline 4 & 41 & 0 & Intermediate & \\
\hline 0 & 0 & 45 & Worn-out & \\
\hline \multicolumn{5}{|c|}{ ANN classifier } \\
\hline 40 & 5 & 0 & Good Tool & \multirow{3}{*}{94.80} \\
\hline 2 & 43 & 0 & Intermediate & \\
\hline 0 & 0 & 45 & Worn-out & \\
\hline
\end{tabular}

Table 10: Confusion matrix of the fused data in Wavelet domain

\begin{tabular}{|c|c|c|c|c|}
\hline \multicolumn{5}{|c|}{ Decision Tree classifier } \\
\hline $\begin{array}{c}\text { Good tool } \\
\text { Class A }\end{array}$ & $\begin{array}{c}\text { Intermediate } \\
\text { Class B }\end{array}$ & $\begin{array}{l}\text { Worn-out } \\
\text { Class C }\end{array}$ & Tool condition & $\begin{array}{l}\text { Classification } \\
\text { efficiency, \% }\end{array}$ \\
\hline 42 & 2 & 1 & Good Tool & \multirow{3}{*}{96.29} \\
\hline 2 & 43 & 0 & Intermediate & \\
\hline 0 & 0 & 45 & Worn-out & \\
\hline \multicolumn{5}{|c|}{ Naive Bayes classifier } \\
\hline 40 & 5 & 0 & Good Tool & \multirow{3}{*}{91.85} \\
\hline 4 & 41 & 0 & Intermediate & \\
\hline 1 & 1 & 43 & Worn-out & \\
\hline \multicolumn{5}{|c|}{ SVM classifier } \\
\hline 41 & 4 & 0 & Good Tool & \multirow{3}{*}{95.56} \\
\hline 1 & 43 & 1 & Intermediate & \\
\hline 0 & 0 & 45 & Worn-out & \\
\hline \multicolumn{5}{|c|}{ ANN classifier } \\
\hline 45 & 0 & 0 & Good Tool & \multirow{3}{*}{100} \\
\hline 0 & 45 & 0 & Intermediate & \\
\hline 0 & 0 & 45 & Worn-out & \\
\hline
\end{tabular}

\subsection{Performance of classifiers based on classification efficiency}

The extracted features of $\mathrm{AE}$ and vibration signals in timedomain, frequency domain and time-frequency domain are trained using machine learning algorithms. After training the classifiers are tested using the tool condition features of $\mathrm{AE}$ and vibration data. Classification efficiency of the algorithms considered separately without feature level fusion is studied using confusion matrix. The classification efficiencies of machine learning classifiers without fusion are shown in Figure 20.

Time - frequency analysis has been carried out by extracting wavelet coefficients from the various wavelets of $\mathrm{AE}$ and vibration signals. Wavelet coefficients were extracted using haar, daubechies (db11, db12, db13 and db14), biorthogonal (bior 3.9, bior 4.4 and bior 5.5) and reverse biorthogonal (rbio 4.4, rbio 5.5 and rbio 6.8) wavelets. The performances of the wavelets are shown in the Table 11 for vibration and AE data. 
Table 11: Classification Efficiency in wavelet domain for classifiers (non-fused $\mathrm{AE}$ and Vibration data)

\begin{tabular}{|l|l|l|l|l|l|l|l|l|}
\hline \multirow{2}{*}{ Wavelet } & \multicolumn{3}{|l|}{ Classifier Efficiency, \% (Vibration) } & \multicolumn{3}{|c|}{ Classifier Efficiency, \% (AE) } \\
\cline { 2 - 9 } & DTA & NB & SVM & ANN & DTA & NB & SVM & ANN \\
\hline bior 3.9 & 88.88 & 83.70 & 95.56 & 66.70 & 84.00 & 76.00 & 83.70 & $\mathbf{1 0 0 . 0 0}$ \\
\hline bior 4.4 & 77.77 & 80.00 & 91.86 & 71.10 & $\mathbf{8 6 . 6 6}$ & 79.33 & $\mathbf{9 0 . 0 0}$ & $\mathbf{1 0 0 . 0 0}$ \\
\hline bior 5.5 & 72.59 & 72.59 & 95.56 & 96.30 & 84.33 & 78.00 & $\mathbf{9 0 . 0 0}$ & $\mathbf{1 0 0 . 0 0}$ \\
\hline db 11 & 75.55 & 71.85 & 93.43 & 97.80 & 86.00 & 77.00 & 89.70 & $\mathbf{1 0 0 . 0 0}$ \\
\hline db 12 & 71.11 & 68.14 & 98.52 & 98.50 & 85.66 & 76.66 & 88.00 & $\mathbf{1 0 0 . 0 0}$ \\
\hline db 13 & 81.48 & 65.92 & 93.43 & 99.30 & 85.00 & 75.00 & 89.00 & $\mathbf{1 0 0 . 0 0}$ \\
\hline db 14 & 75.55 & 65.18 & $\mathbf{9 9 . 2 6}$ & 99.30 & 84.33 & 74.66 & 89.70 & $\mathbf{1 0 0 . 0 0}$ \\
\hline haar & $\mathbf{9 4 . 0 7}$ & $\mathbf{9 1 . 8 5}$ & 94.82 & 93.30 & 72.66 & 74.66 & 84.40 & $\mathbf{1 0 0 . 0 0}$ \\
\hline rbio 4.4 & 82.96 & 82.22 & 94.08 & 66.70 & 86.66 & 79.66 & 89.70 & $\mathbf{1 0 0 . 0 0}$ \\
\hline rbio 5.5 & 86.66 & 82.22 & 95.56 & 91.10 & 84.33 & 79.33 & 89.70 & $\mathbf{1 0 0 . 0 0}$ \\
\hline rbio 6.8 & 75.55 & 72.59 & 98.52 & $\mathbf{9 9 . 3 0}$ & 85.66 & 76.00 & $\mathbf{9 0 . 0 0}$ & $\mathbf{1 0 0 . 0 0}$ \\
\hline
\end{tabular}

In time-frequency (wavelet) domain, Using AE data, ANN classifier is producing $100 \%$ classification efficiency for all wavelets considered in this study. For the vibration data rbio 6.8 wavelet is producing classification efficiency of $99.30 \%$ for vibration data. SVM classifier was able to classify the $\mathrm{AE}$ data with $90 \%$ classification efficiency for 3 wavelets namely bior 4.4, bior 5.5 and rbio 6.6. For vibration data, db14 wavelet is producing $99.26 \%$ classification efficiency. Naïve bayes classifier is able to achieve $91.85 \%$ classification efficiency using haar wavelet for vibration data and $79.66 \%$ efficiency for rbio 4.4 wavelet with $\mathrm{AE}$ data. Decision tree classifier is producing classification efficiency of $94.07 \%$ for vibration data and $86.66 \%$ for $\mathrm{AE}$ data using haar and bior 4.4 wavelets respectively. Classification efficiencies of best performing wavelets (time - frequency domain) are shown in the Figure 20.

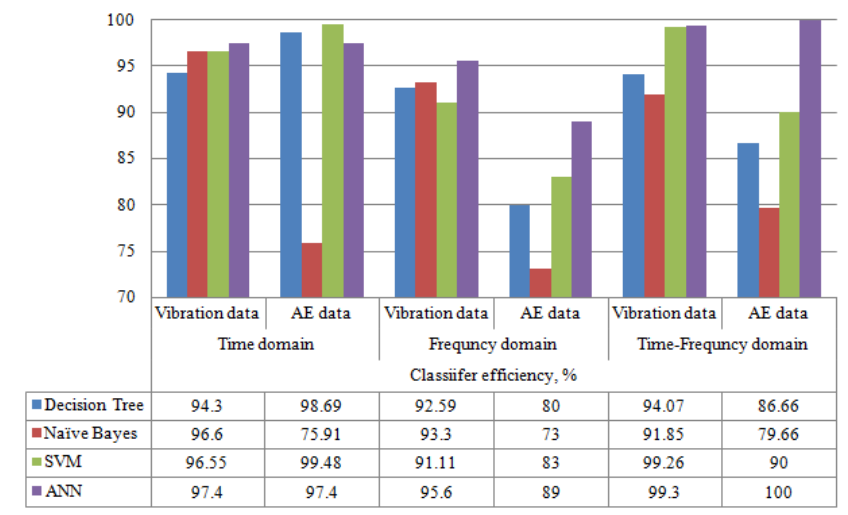

Figure 20. Classification efficiency of machine learning algorithms without feature-level fusion

The performance of machine learning algorithms in frequency domain is not as good as performance in time domain and time-frequency domain. Frequency domain analysis was found to be constructive in analyzing the stationary signals. The process considered in this study is milling, which is an intermittent cutting process and produces a non-stationary signal. This may be the reason for not getting good results in frequency domain.
In the next step, feature level data fusion of $\mathrm{AE}$ and vibration data is carried out in time-domain, frequency domain and time-frequency domain. The results are shown in Figure 21. From the results, it is found that the feature level fusion is more effective in time domain compared to frequency domain and wavelet transforms. Except decision tree, all the other three machine learning algorithms considered in this study are giving their maximum performance in time domain and producing $100 \%$ classification efficiency for the test cases considered for predicting the tool condition. ANN is producing $100 \%$ classification efficiency in time domain and time-frequency domain. Variant of SVM, C-SVC is able to produce $100 \%$ classification efficiency in time-domain.

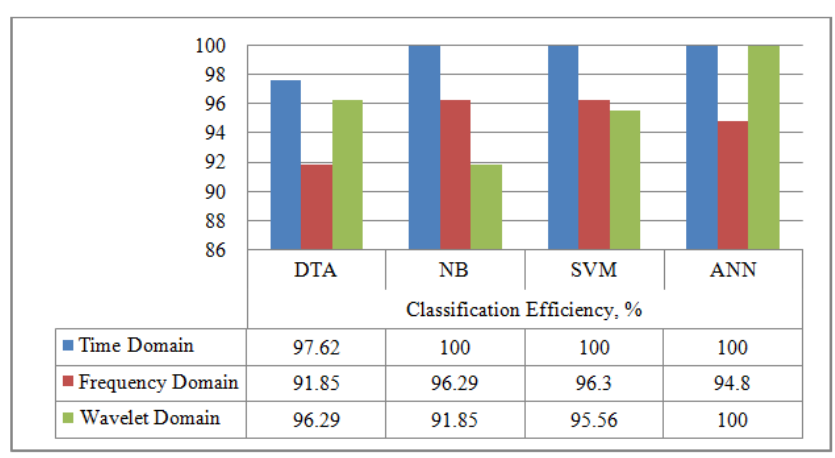

Figure 21. Classification efficiency of machine learning algorithms with feature-level fusion

Overall, from the results it is observed that fusion methodology adopted in this study is improving the classification efficiency in time-domain, frequency domain and time-frequency domain. Feature level fusion is appears to be a promising area of research in the area of tool condition monitoring. Using the fusion approach a reliable real-time tool condition monitoring systems can be developed.

\section{Conclusions}

In this study, an experimental set-up was established to classify the tool condition using vibration and acoustic emission signals in a high speed milling center. Dominant features of the vibration and acoustic emission signals were extracted using decision tree based algorithm for tool condition classification in time-domain, frequency-domain and time-frequency domain. C4.5 decision tree, Support Vector Machine (SVM), Naive Bayes and Artificial Neural Networks (ANN) were used for tool condition classification.

For the non-fused system in time-domain, for vibration data ANN classifier is producing maximum classification efficiency of $97.4 \%$ and for the AE data, SVM is producing classification efficiency of $99.48 \%$. In frequency domain, ANN is found to be predicting the maximum classification efficiency of $95.56 \%$ and $89 \%$ for the vibration data and $\mathrm{AE}$ data respectively. In time -frequency domain (Wavelet), 
ANN is out-performing the decision tree, SVM and Naïve bayes classifiers for $\mathrm{AE}$ and Vibration data.

The performance of Machine learning algorithms in frequency-domain is not as good as performance in time domain. Using the vibration signatures, the Machine learning algorithms produced better classification efficiency than the acoustic emission signature. Among all the Machine learning algorithms considered in frequency domain, ANN using vibration signature has produced a maximum classification efficiency of $95.56 \%$.

In order to capture the time-frequency resolution of the vibration and acoustic signal, wavelets were extracted using discrete wavelet transform. A total of 11 wavelets from the families of daubechies, haar, bi-orthogonal and reverse biorthogonal were considered. The performance of C- SVC, is consistent and producing better classification efficiency in all the wavelets for the vibration data. ANN is the best performing algorithm and producing a classification efficiency of $100 \%$ for all the wavelets using acoustic emission data. The performance of algorithms using acoustic emission signals are better comparing to vibration signals in wavelet domain.

Classification efficiencies of the algorithms were improved by adopting feature level fusion of vibration and acoustic emission data. Feature level fusion is more effective in timedomain compared to frequency domain and time-frequency domain (wavelet transforms). In time-domain, naïve bayes, SVM and ANN classifiers are producing $100 \%$ classification efficiency for test cases considered for predicting the tool conditions. It is also to be noted that ANN classifier is producing $100 \%$ classification efficiency in time-domain and also in time -frequency domain (Wavelet). The data fusion methodology adopted in this work is proved to be useful in developing a reliable online tool condition monitoring system.

\section{ACKNOWLEDGEMENT}

This research is supported by Directorate of Extramural Research \& Intellectual Property Rights (ER \& IPR), Defense Research and Development Organization (DRDO), ERIP/ER/0803740/M/01/1194, 13.1.2010.

\section{REFERENCES}

Acharya, S. (2015). Distributed Detection and Fusion in Parallel Sensor Architectures. Doctoral dissertation. Drexel University.

Aliustaoglu, C., Ertunc, H. M., Ocak, H. (2009): Tool wear condition monitoring using a sensor fusion model based on fuzzy inference system, Mechanical Systems and Signal Processing, 23, 539-546.

Arun, A., Rameshkumar, K., Unnikrishnan, D., and Sumesh, A. (2018). Tool condition monitoring of cylindrical grinding process using acoustic emission sensor. ICMMM-2017. Materials Today: Proceedings.

Bhuiyan, M. S. H., Choudhury, I. A., Yusoff, N., and Dawal, S. Z. M. (2016). Application of acoustic emission sensor to investigate the frequency of tool wear and plastic deformation in tool condition monitoring. Measurement, 32, 208-217.

Carbonell, J. G., Michalski, R. S., and Mitchell, T. M. (1983). An overview of machine learning. In Machine learning (pp. 3-23). Springer Berlin Heidelberg.

Cortes, C., and Vapnik, V. (1995). Support-vector networks. Machine learning, 20(3), 273-297.

Dimla, D. E. (2002). The correlation of vibration signal features to cutting tool wear in a metal turning operation. The International Journal of Advanced Manufacturing Technology, 19(10), 705-713.

Dornfeld, D. A. (1991). Monitoring of the machining process by means of acoustic emission sensors. In Acoustic Emission: Current Practice and Future Directions. ASTM International.

Elangovan, M., Devasenapati, S. B., Sakthivel, N. R., \& Ramachandran, K. I. (2011-b). Evaluation of expert system for condition monitoring of a single point cutting tool using principle component analysis and decision tree algorithm. Expert Systems with Applications, 38(4), 4450-4459.

Elangovan, M., Ramachandran, K. I., and Sugumaran, V. (2010). Studies on Bayes classifier for condition monitoring of single point carbide tipped tool based on statistical and histogram features. Expert Systems with Applications, 37(3), 2059-2065.

Elangovan, M., Sugumaran, V., Ramachandran, K. I., and Ravikumar, S. (2011-a). Effect of SVM kernel functions on classification of vibration signals of a single point cutting tool. Expert Systems with Applications, 38(12), 15202-15207.

Gunatilaka, A. H., and Baertlein, B. A. (2001). Feature-level and decision-level fusion of noncoincidently sampled sensors for land mine detection. IEEE transactions on pattern analysis and machine intelligence, 23(6), 577589.

Hall, D. L., \& Llinas, J. (1997): An introduction to multisensor data fusion. Proceedings of the IEEE, 85(1), 6-23.

Han, X., and Wu, T. (2013). Analysis of acoustic emission in precision and high-efficiency grinding technology. The International Journal of Advanced Manufacturing Technology, 67(9-12), 1997-2006.

Hase, A., Wada, M., Koga, T., and Mishina, H. (2014). The relationship between acoustic emission signals and cutting phenomena in turning process. The International Journal of Advanced Manufacturing Technology, 70(58), 947-955. 
Hutton, D. V., and Hu, F. (1999). Acoustic emission monitoring of tool wear in end-milling using timedomain averaging. Journal of manufacturing science and engineering, 121(1), 8-12

Inasaki, I. (1998). Application of acoustic emission sensor for monitoring machining processes. Ultrasonics, 36(1), 273-281.

Karpuschewski, B., Wehmeier, M., and Inasaki, I. (2000). Grinding monitoring system based on power and acoustic emission sensors. CIRP Annals-Manufacturing Technology, 49(1), 235-240.

Krishnakumar, P., Rameshkumar, K., and Ramachandran, K. I. (2015). Tool wear condition prediction using vibration signals in high speed machining (HSM) of titanium (Ti6Al-4V) alloy. Procedia Computer Science, 50, 270275.

Krishnakumar, P., Rameshkumar, K., and Ramachandran, K. I. (2018). Machine learning based tool condition classification using acoustic and vibration data in high speed milling process using wavelet features. Intelligent Decision Technologies, 12 265-282.

Zhu,K., Wong,Y.S., and Hong, G.S. (2009): Wavelet analysis of sensor signals for tool condition monitoring: A review and some new results, International Journal of Machine Tools and Manufacture, 49(7-8), 537-553.

Lamraoui, M., Thomas, M., El Badaoui, M., and Girardin, F. (2014). Indicators for monitoring chatter in milling based on instantaneous angular speeds. Mechanical Systems and Signal Processing, 44(1), 72-85.

Lauro, C. H., Brandão, L. C., Baldo, D., Reis, R. A., and Davim, J. P. (2014). Monitoring and processing signal applied in machining processes-A review. Measurement, 58, 73-86.

Marinescu, I., and Axinte, D. A. (2008). A critical analysis of effectiveness of acoustic emission signals to detect tool and work piece malfunctions in milling operations. International Journal of Machine Tools and Manufacture, 48(10), 1148-1160. 17.

Quinlan, J. R. (1993). C4. 5: Programming for machine learning. Morgan Kauffmann, 38.

Ravindra, H. V., Srinivasa, Y. G., and Krishnamurthy, R. (1997). Acoustic emission for tool condition monitoring in metal cutting. Wear, 212(1), 78-84.

Roth, J. T., Djurdjanovic, D., Yang, X., Mears, L., and Kurfess, T. (2010). Quality and inspection of machining operations: tool condition monitoring. Journal of Manufacturing Science and Engineering, 132(4), 041015.

Rumelhart, D. E., Hinton, G. E., and Williams, R. J. (1988). Learning representations by back-propagating errors. Cognitive modeling, 5(3), 1.
Russell, S. J., Norvig, P., Canny, J. F., Malik, J. M., and Edwards, D. D. (2003). Artificial intelligence: a modern approach (Vol. 2). Upper Saddle River: Prentice hall.

Saimurugan, M., Nithesh, R.(2016) : Intelligent fault diagnosis model for rotating machinery based on fusion of sound signals, International Journal of Prognostics and Health Management, 018, 2153-2648.

Salgado, D. R., Alonso, F. J., Cambero, I., and Marcelo, A. (2009). In-process surface roughness prediction system using cutting vibrations in turning. The International Journal of Advanced Manufacturing Technology, 43(12), 40-51.

Shi, D., and Gindy, N. N. (2007). Tool wear predictive model based on least squares support vector machines. Mechanical Systems and Signal Processing, 21(4), 1799-1814.

Sick, B. (2002). On-line and indirect tool wear monitoring in turning with artificial neural networks: a review of more than a decade of research. Mechanical Systems and Signal Processing, 16(4), 487-546.

Cho, S., Binsaeid, S., and Asfour, S. (2009): Design of multi sensor fusion-based tool condition monitoring system in end milling, International Journal of Advanced Manufacturing Technology, 46(5-8), 681-694.

Stavropoulos, P., Chantzis, D., Doukas, C., Papacharalampopoulos, A., and Chryssolouris, G. (2013). Monitoring and control of manufacturing processes: A review. Procedia CIRP, 8, 421-425.

Teti, R., Jemielniak, K., O’Donnell, G., and Dornfeld, D. (2010). Advanced monitoring of machining operations. CIRPAnnals-Manufacturing

Technology, 59(2), 717-739.

Banerjee, T.P. and Das, S. (2012): Multi-sensor data fusion using support vector machine for motor fault detection, Information Sciences, 217, 96-107.

Wang, P., Meng, Q., Zhao, J., Li, J., and Wang, X. (2011). Prediction of machine tool condition using support vector machine. In Journal of Physics: Conference Series (Vol. 305, No. 1, p. 012113). IOP Publishing.

Wang, W.H., Wong, Y.S., Hong, G.S., and Zhu, K.P. (2007): Sensor fusion for on-line tool condition monitoring in milling, International Journal of Production Research, 45(21), 5095-5116.

Zhang, C., Yao, X., Zhang, J., and Jin, H. (2016). Tool Condition Monitoring and Remaining Useful Life Prognostic Based on a Wireless Sensor in Dry Milling Operations. Sensors, 16(6), 795.

Zhong, W., Zhao, D., and Wang, X. (2010). A comparative study on dry milling and little quantity lubricant milling based on vibration signals. International Journal of Machine Tools and Manufacture, 50(12), 1057-1064. 


\section{BIOGRAPHIES}

P. Krishnakumar

He has received his master degree in Computer Integrated Manufacturing in the year 2000 and received his $\mathrm{PhD}$ in the area of machine condition monitoring. Currently, he is working as an Assistant Professor in the Department of Mechanical Engineering, Amrita Vishwa Vidyapeetham, Coimbatore, India. His research interests include condition monitoring and machining.

\section{K. Rameshkumar}

He has received his M.E and PhD in Production Engineering in the year 2007. Currently, he is working as a Professor in the Department of Mechanical Engineering, Amrita Vishwa Vidyapeetham, Coimbatore, India. His research interests include tool condition monitoring, signal processing, machining dynamics, optimization and simulation of manufacturing systems.

\section{K.I. Ramachandran}

He has received his M.Tech at IIT Kanpur, India in 1988. Then, he completed his PhD at IIT Madras, India in 1993. In 1994, he started his career in teaching profession at Amrita Institute of Technology, Coimbatore. Currently, he is working as a Professor at Amrita Vishwa Vidyapeetham, Coimbatore, India. His research interests include condition monitoring, machining, and signal processing. 